\title{
A estratégia brasileira de desenvolvimento e a crise financeira internacional
}

Fabio Doria Scatolin*

RESUMO - A discussão sobre possíveis estratégias de desenvolvimento para o Brasil começou a ser mais debatida na academia nos últimos meses. O ano de 2010 será importante para este debate em função das eleições presidenciais. $O$ objetivo destas notas é de um lado fazer uma breve avaliação das principais políticas adotadas pelo país nos últimos 50 anos e de outro lado discutir duas diferentes alternativas de estratégias de desenvolvimento para o país nos médio prazo.

Palavras-chave: Estratégia de desenvolvimento. Brasil e a inserção internacional.

Desde a década de 50 do século passado a estratégia brasileira de desenvolvimento tem tido na industrialização via substituição de importações e na poupança externa seus pilares mestres. A atual crise financeira internacional e a consequente interrupção parcial dos fluxos de capitais tem gerado um interessante debate em nosso país sobre a conveniência e mesmo a sustentabilidade desta estratégia de desenvolvimento no futuro. O objetivo deste artigo é analisar alguns pontos envolvidos nesta temática.

Os governos de Getúlio Vargas (1950-1954) e Juscelino Kubitschek (1956-1960) são um marco divisor na história econômica do país. Para o bem e para o mal não só as bases da estratégia de industrialização brasileira foram definidas, mas principalmente o padrão de financiamento da economia local foi estabelecido naquela década. O crescimento da demanda doméstica, impulsionada pelo investimento público, privado nacional e multinacional e a utilização de empréstimos internacionais tem sido os elementos centrais nesta estratégia. Inicialmente via investimento externo direto (IED) e em seguida via empréstimos internacionais, o fluxo de capitais externos tem sido decisivo para o equilíbrio e mesmo desequilíbrio da economia brasileira nos últimos 50 anos. Esta estratégia de industrialização funcionou bem por quase três décadas (1950-1980) onde a constituição de uma estrutura produtiva diversificada e integrada propiciou um ciclo de crescimento próximo a 7\% a.a. Esta estratégia foi denominada pelo sociólogo Fernando Henrique Cardoso na época de uma estratégia de desenvolvimento dependente e associada. A dependência tecnológica e financeira e a

\footnotetext{
* Doutor em Economia pela Universidade de Londres. Professor Associado do Departamento de Economia da Universidade Federal do Paraná. Endereço eletrônico: scatolin@ufpr.br.
} 
concentração de renda eram os aspectos negativos desta estratégia. No entanto nos próximos 25 anos esta estratégia se mostrou ainda mais perversa com a emergência de desequilíbrio interno e principalmente de desequilíbrio externo que condenaram o país a um ciclo de baixo crescimento econômico.

A permanência e racionalidade desta estratégia durante este tempo tem estado assentada em dois planos. Um primeiro plano teórico está relacionado ao que os economistas e demais membros da elite brasileira acreditam ser determinantes para o crescimento do país. Um segundo plano está relacionado às mudanças ocorridas no sistema financeiro internacional e no padrão e financiamento da economia brasileira no mundo pós-Bretton Woods.

Com relação ao plano teórico ao final da segunda grande guerra o pensamento keynesiano passou a ser hegemônico na academia. Junto com ele diversos modelos teóricos foram desenvolvidos procurando explicar as flutuações de curto e de longo prazo. Um destes modelos que teve grande influência na forma de pensar de toda uma geração de economistas brasileiros foi o modelo de Harrod Domar. Neste modelo a carência de poupança doméstica necessária para financiar o investimento e o crescimento de um país poderia ser complementada com a poupança externa. Dessa forma IED e empréstimos externos eram as contrapartidas necessárias para um país em desenvolvimento acelerar seu processo de transformação. No entanto passados mais de 50 anos este modelo está bastante desacreditado no mundo acadêmico. $\mathrm{O}$ fenômeno do crescimento é muito mais complexo do que aquele modelo simplificado supunha. A inovação e as instituições, por exemplo, não tinham a menor importância nos modelos do pós-guerra e hoje são considerados por diversas correntes como variáveis centrais no processo de crescimento e transformação das economias em desenvolvimento. Especificamente os críticos (Rodrick) têm demonstrado que não existe correlação e mesmo relação de causalidade entre a poupança externa, o investimento e o crescimento.

Com relação ao segundo plano, ao padrão de financiamento da economia brasileira o crescimento dos fluxos de capitais tem sido impressionante nos últimos 50 anos. O padrão Bretton Woods ao estabelecer no pós-Segunda Guerra as regras do funcionamento do sistema financeiro internacional, possibilitou um crescimento imenso do comércio internacional, dos investimentos e dos demais fluxos de capitais. Mesmo países com grandes dimensões de mercado doméstico como a China e EUA se beneficiaram desta nova fase das finanças internacionais. O Brasil não foi exceção. Os fluxos de IED tem sido não somente fluxos de 
capitais, mas também mecanismo de transferências de tecnologia. O problema é que com a evolução do sistema de Bretton Woods e sua transformação de um regime de câmbio fixo para câmbio flutuante nos anos 70 e a consequente explosão de novos produtos financeiros cresceu também a instabilidade financeira. Eichegreen encontrou evidências de mais de 120 crises cambiais entre a década de 70 e a primeira década deste milênio. Em nenhum outro período na história mundial foi observado tantas crises como foi observado no passado recente. O Brasil passou por pelo menos quatro crises cambiais sérias entre a segunda metade dos anos 70 e hoje.

Se a crise financeira atual tivesse demorado uns dois anos a mais para ocorrer provavelmente teria provocado muito mais estragos em nossa economia do que tem provocado em função novamente da opção de crescer com poupança externa ter sido implicitamente adotada a partir de 2007. No cerne da crise financeira internacional atual está o que Ben Bernanke denominou de excesso de poupança mundial. Superávits e déficits estruturais nos balanços de pagamentos dos países estão na origem dos desequilíbrios das finanças internacionais. Países como a China e mais recentemente os países da OPEP passaram a acumular superávits astronômicos que precisam ser reciclados no mercado financeiro internacional. A expansão do consumo norte-americano é a contrapartida destes desequilíbrios. Os norte-americanos já deixaram claros que farão seus ajustes internos voltando a ser uma sociedade menos consumista com um esforço maior de poupança. A China em particular tem adotado uma estratégia de desenvolvimento desde os anos 80, denominada de export led growth; onde parte do crescimento do consumo doméstico é desviada para os investimentos e à exportação. Uma estratégia de desenvolvimento muito bem sucedida até o presente, mas que com a crise financeira internacional está sendo questionada em função da incapacidade permanente dos EUA e de outros países de absorverem este excesso de poupança. Com certeza os chineses e os norte-americanos vão saber ajustar suas estratégias de desenvolvimento ao novo mundo que começa a ser construído a partir da crise atual. A hegemonia americana diferente dos anos 70 do século passado, agora de fato está em jogo. A solução para a crise ainda não foi encontrada.

E a estratégia de desenvolvimento brasileira? Qual é a direção a tomar? Com relação ao primeiro plano teórico é preciso que as elites brasileiras parem de ver poupança externa como a panacéia para o crescimento e a transformação do país. O país precisa priorizar outras variáveis como a inovação, as instituições e o esforço de melhoria educacional. São estas 
variáveis que as evidências empíricas e os novos modelos de crescimento consideram relevantes no processo de transformação das nações em desenvolvimento.

Com relação ao segundo plano do padrão de financiamento da economia brasileira não está claro ainda quais vão ser as novas regras do novo sistema financeiro internacional. Até mesmo não está claro se teremos novas regras! Neste mundo de incerteza, onde de um lado, as velhas regras continuam valendo como a desregulamentação excessiva e a instabilidade congênita e de outro lado, e o novo ainda está em gestação e EUA, China e o G20 estão ainda na fase de entender o que está acontecendo, é uma insensatez imaginar que a crise financeira passou e que podemos voltar a crescer estimulando a demanda doméstica e atraindo poupança externa como fizemos nos últimos 50 anos. A severidade da crise financeira atual já é o suficiente para parar de brincar de repetir erros do passado e condenar o país a mais um ciclo de estagnação. A previsão para o próximo ano é que o déficit em transações correntes vai ultrapassar novamente os 3\% e desta forma criar uma instabilidade adicional que o país não precisava passar. A correção do câmbio não é feita porque o $\mathrm{BC}$ insiste em olhar exclusivamente o equilíbrio interno. Países que tem um projeto de nação há muito tempo administram sua taxa de câmbio conforme seus objetivos estratégicos

Construir uma estratégia de futuro para o país significa repensar a estratégia de crescimento do país e sua relação com o resto do mundo. Nesta perspectiva pelo menos duas alternativas se vislumbram no debate econômico atual. Uma primeira estratégia é apoiar o desenvolvimento de uma indústria intensiva em recursos naturais e se especializar naquelas cadeias produtivas em que o país tem uma vantagem comparativa estabelecida. Aliada a esta especialização o desenvolvimento de um sistema financeiro que ao captar poupança externa financia estas novas atividades agroexportadoras bem como um setor non-tradables que cresce na medida em que a demanda doméstica cresce é o sonho dos liberais brasileiros. A lembrança da estratégia australiana e canadense é normalmente citada por autores que defendem esta estratégia. O problema é que estes países de dimensões continentais como o Brasil tem uma diferença que é fundamental; o reduzido tamanho de suas populações. Nesta estratégia o câmbio valorizado não é uma restrição central para determinadas cadeias como a mineral, ou mesmo a sucroalcooleira visto que o crescimento destes setores depende mais da demanda externa de países como a China e de outros preços como o petróleo do que da taxa real de câmbio.

Uma segunda estratégia reside em não somente apoiar o setor do agronegócio e suas cadeias nas exportações, mas também ter em mente que as relações intersetoriais destas 
cadeias com o núcleo da estrutura industrial brasileira como a metal-mecânica, a química, a farmacêutica, entre outras indústrias, são fundamentais não só para a competitividade do conjunto do setor tradable brasileiro, mas também na geração de emprego da economia brasileira e, mais importante de tudo, na capacidade endógena da economia local de gerar inovações para o conjunto da estrutura produtiva. O próprio agribusiness brasileiro é resultado de um processo de avanço da industrialização e da mudança estrutural, onde setores da industria pesada como química, metal mecânica e farmacêutica se implantaram no país na segunda metade do século passado. Uma indústria diversificada e centrada nos setores de média e alta tecnologia e de recursos naturais como verdadeiros blocos de desenvolvimento e inovação articulados constitui a alternativa civilizadora para o país. As vantagens comparativas que o país tem hoje no setor de petróleo, no setor agroindustrial e mineral foram fabricadas, resultado de anos de investimentos em P\&D e da aplicação de conhecimento nas áreas da genética, mecânica, química e em tecnologias de informação e comunicação (Tics). A lembrança de uma matriz industrial mais diversificada e integrada como tem sido o caso dos EUA no pós-guerra, que junto com o agribusiness mais avançado do mundo manteve uma indústria de média e alta tecnologia com a geração de empregos qualificados é a melhor referência para a estratégia brasileira. Nesta estratégia a questão do câmbio real é central. Os setores vinculados ao miolo de nossa estrutura industrial de média tecnologia e mesmo de determinadas cadeias produtivas como a de carnes (aves, suíno e gado), café, soja e milho exigem uma taxa de câmbio competitiva para fazer frente aos principais competidores no mercado internacional. Dentro desta visão a geração de superávits nas transações correntes e a consequente geração de poupança doméstica passa a ser garantia de um desenvolvimento sustentável no longo prazo. Finalmente, ter prejuízo operacional, comprar derivativos no mercado futuro e apostar na valorização da moeda local (Real) como sendo inevitável não é uma estratégia de desenvolvimento de longo prazo para qualquer país, mas sim é uma estratégia de cassino. Apostar novamente apenas no crescimento do mercado interno com déficits crescentes nas transações correntes não é uma estratégia sustentável de desenvolvimento, é apenas uma estratégia eleitoral. 
